
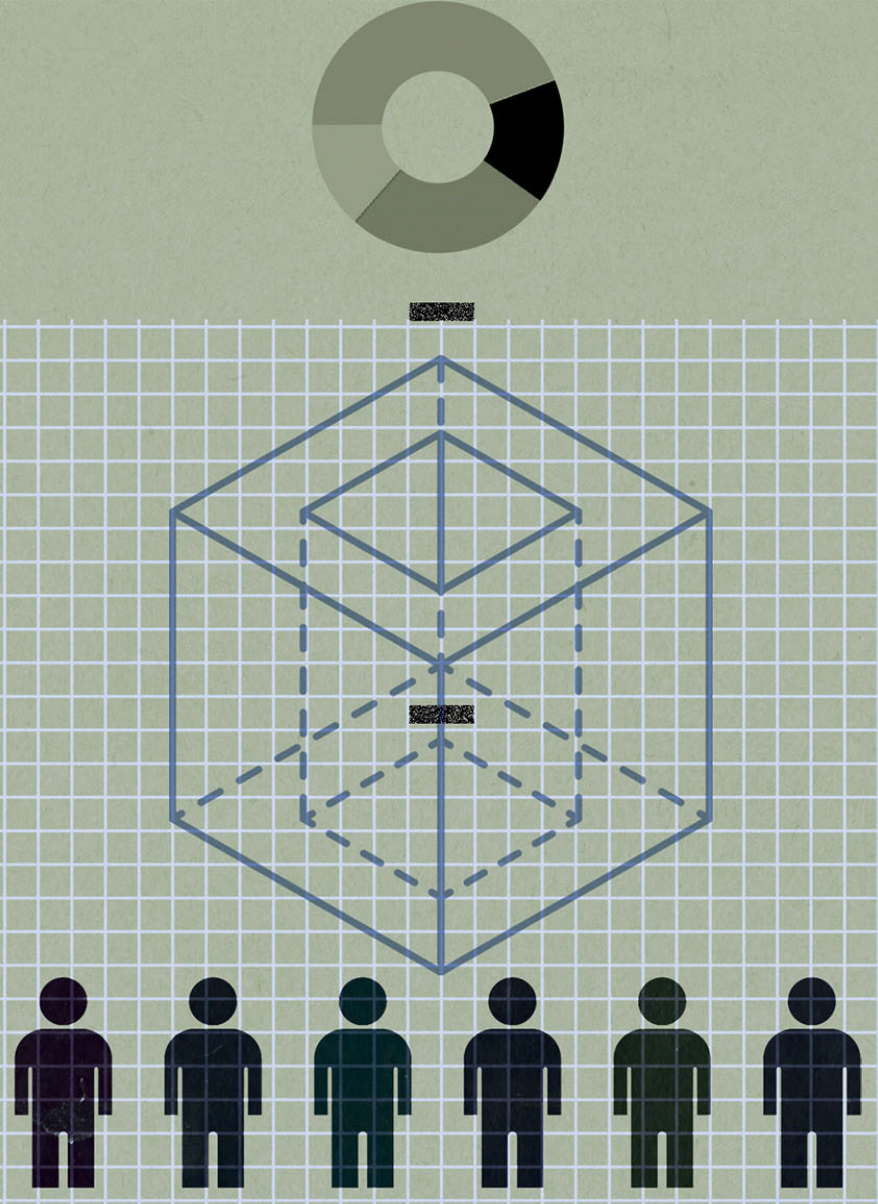

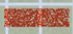

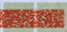

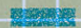

$\sin 2$
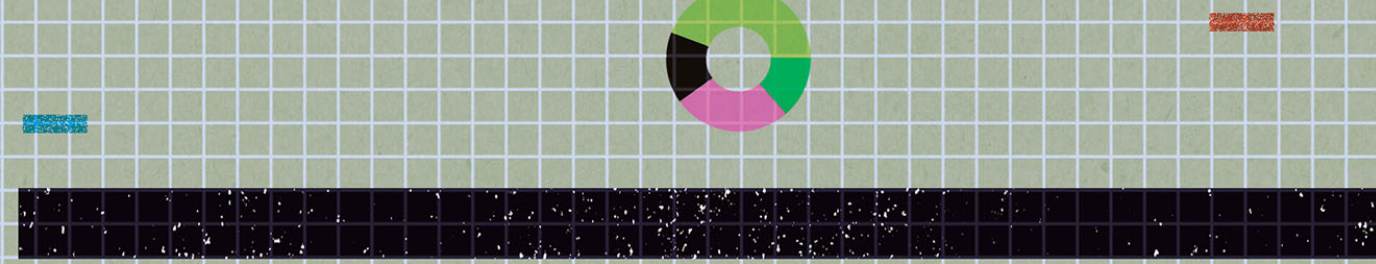

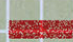




\title{
Avaliação endógena e a legitimidade das políticas públicas: a experiência da Ouvidoria Geral do Município de Campinas (SP)
}

\author{
Endogenous Assessment and Public Policies \\ Legitimacy: The Compinas county (SP) \\ general ombudsmanship experience
}

Camila Gonçalves de Mớrio*

\begin{abstract}
Resumo
O intuito deste artigo é refletir sobre o processo de avaliação e a legitimidade das políticas públicas a partir da experiência de avaliação endógena da Ouvidoria Geral do município de Campinas (SP) entre 2002 e 2009 . Adotando uma perspectiva substantiva de avaliação que incorpore as opiniões e expectativas dos atores que participam diretamente da produção da política - como os burocratas de nível de rua e dos cidadãos usuários diretos - defende-se que no momento da avaliação os valores que perpassam as políticas públicas e questões afeitas à sua legitimidade são cruciais para o entendimento de seus sentidos e dos resultados alcançados.
\end{abstract}

Palavras-chave: ICMS; avaliação endógena; legitimidade; políticas públicas; justiça social.

\begin{abstract}
This paper discusses the public policies process of evaluation and legitimacy considering the endogenous evaluation experience in public sector ombudsman at Campinas municipality (SP - Brasil) over 2002 - 2009. Based on a substantive evaluation approach that considers the opinions and expectations of those actors whom are engaged in the policies production and of the citizens, whom are public policies direct users, the main aim is stand that public policies' background values and legitimacy issues are critical for the evaluation process and to the comprehension of its means and reached results.
\end{abstract}

Keyword: endogenous evaluation; legitimacy; public policies; social justice.

\footnotetext{
* Professora do Programa de Pós-Graduação em Sociologia Política do Instituto Universitário de Pesquisas do Rio de Janeiro - IUPERJ - UCAM (RJ). E-mail: camilagdemario@gmail.com.
} 


\section{INTRODUÇÃO}

Este artigo tem como propósito apresentar uma reflexão teórica sobre a avaliação e a legitimidade das políticas públicas, desembocando em questões que considero devem ser enfrentadas, tanto para a análise acadêmica das políticas públicas como para o processo de avaliação empreendido pelos governos. Reflexões tanto sobre a avaliação como sobre a legitimidade que mobilizam questões complexas e ainda pouco ou superficialmente discutidas pelo campo das políticas públicas brasileiro. Certamente, há mais trabalhos que contribuem com os sentidos e os processos de avaliação, mormente pensando técnicas e métodos, mais do que a legitimidade das políticas públicas.

Como já discuti em trabalhos anteriores (De Mario; Laisner; Granja, 2016), considero que a avaliação deve ser pensada como presente em todos os momentos da elaboração e implementação das políticas públicas, por meio de diferentes formatos e orientada por diversos interesses ao longo do processo, abrangendo uma gama de atores que extrapola aqueles diretamente envolvidos com a produção da política. O que significa pensá-la também como um instrumento de gestão.

Neste artigo, meu argumento central é que precisamos refletir sobre a avaliação de políticas públicas a partir de análises que incluam (1) as ideias e os valores presentes no processo de produção da política e, (2) o papel desempenhado pelos atores envolvidos com a produção e avaliação das políticas - burocratas, produtores da política e os cidadãos usuários. O que requer lidar com a subjetividade e pensar análises substantivas das políticas públicas.

Avaliar uma política pública também significa incorporar questões sobre a legitimidade da política, pois é o que justifica sua existência e manutenção ao longo do tempo. Nesse sentido, entendo que avaliação e legitimidade são relacionais. Como veremos adiante, são vários os elementos substantivos e procedimentais que devemos considerar para refletir sobre a legitimidade. Entretanto, já chamo atenção aqui para a ideia que perpassa esse artigo: a de que a reflexão sobre a legitimidade e os processos de avaliação pressupõem conhecer os valores e as ideias que perpassam a política pública e a sociedade. Valores que orientam, por um lado, o desempenho dos atores envolvidos na produção da política e, por outro, as expectativas e percepções que os usuários têm sobre a política.

A questão central que tem orientado meu trabalho de pesquisa nos últimos anos e que também trago como importante elemento para essa reflexão é a da justiça social. Podemos considerar que uma das finalidades das políticas públicas no contexto brasileiro, principalmente após os anos 1980, é a de promover equidade e melhoria das condições de vida através da implementação de políticas públicas mais inclusivas e próximas das necessidades da população. Termos como equidade, desenvolvimento social, igualdade, inclusão e justiça social entraram no nosso léxico político e também 
acadêmico, e se tornaram questões cada vez mais presentes nas análises preocupadas com os resultados da participação social e das políticas públicas de forma geral.

Essa finalidade expressa na Constituição de 1988 e as expectativas socialmente construídas em torno dela carregam em si uma concepção de justiça social muito próxima da perspectiva liberal-igualitária'. Buscou-se no bojo da luta pela redemocratização a defesa dos direitos fundamentais do homem, aqueles de dimensão liberal, mas também garantir que o Estado fosse responsável pela promoção do desenvolvimento e da igualdade através da institucionalização dos direitos sociais e sua implementação via políticas públicas.

Tratava-se de garantir as liberdades fundamentais, o direito à vida e de buscar um equilíbrio entre esses valores (os liberais) e aqueles valores comunitários voltados para o reconhecimento da igualdade dos cidadãos. Liberdade e igualdade são valores que nas democracias modernas competem entre si, e que no Brasil foram plasmados na bandeira da cidadania democrática levantada pelos grupos de esquerda que almejavam a construção de uma sociedade para a qual a igualdade não fosse apenas um status moral.

Nesse roteiro as políticas públicas cumprem papel fundamental e passam a ser orientadas por esses e outros valores de fundo conflitantes, e por vezes antagônicos, disputados entre pelo menos dois projetos políticos que passam a ocupar o Estado a partir dos anos 1990, o democrático participativo e o neoliberal.

Por essa razão, defendo que a justiça social precisa ser mais tematizada e ocupar posição relevante para pensarmos tanto a avaliação como a legitimidade das políticas públicas. Isso implica no fortalecimento de um viés de pesquisa substantivo, ainda marginal e contra hegemônico na tradição de estudos de políticas públicas, e no desenvolvimento de métodos de pesquisa que nos permitam compreender o impacto das ideias e dos valores sobre os resultados alcançados pelas políticas públicas.

Outro ponto que quero aqui defender é a importância de incorporar nesse escopo de análise os "burocratas de nível de rua" e os cidadãos usuários da política, atores fundamentais para a avaliação e para e compreensão do processo de legitimidade da política, normalmente negligenciados pela literatura.

Inicio esse artigo com apontamentos sobre as definições mais consensuais da literatura sobre avaliação das políticas públicas. Em seguida, desenvolvo uma reflexão sobre o conceito de legitimidade das políticas públicas, demonstrando a relação que se estabelece entre essa e a avaliação, buscando problematizar elementos que considero relevantes para pensarmos a legitimidade das políticas públicas no contexto brasileiro.

Apresentarei como base do meu argumento sobre o conceito e os processos de avaliação endógena em políticas públicas reflexões elaboradas a partir da minha experiência enquanto gestora e conselheira consultiva da Ouvidoria Geral do Município de Campinas (SP) entre os anos de 2002 e 2009. Experiência que nos possibilita refletir sobre o papel dos burocratas de nível de rua e dos usuários para a avaliação das políticas públicas. 


\section{AVALIAÇĀO E LEGITIMIDADE DAS POLÍTICAS PÚBLICAS: PERSPECTIVAS E POSSIBILIDADES}

Apesar de a avaliação de políticas públicas não ser uma atividade recente, sua prática no âmbito das ciências sociais ainda é incipiente. Trata-se de um momento da análise de políticas públicas marcado por diferentes noções e métodos que enfrentam vários desafios teóricos e práticos. Desafios que também se colocam para o campo de análise das políticas públicas, de forma mais ampla.

No Brasil é a partir dos anos 1990 que a temática da avaliação das políticas públicas surge com mais intensidade e, principalmente, enquanto prática de gestão, buscando responder aos desafios cotidianos da política e também como resposta às exigências impostas por organismos internacionais ${ }^{2}$, ainda com pouco espaço na agenda acadêmica. As avaliações são comumente feitas sob encomenda dos gestores por agentes e agências externas, incumbidas de realizar diagnósticos.

Em contraposição às concepções de avaliação instrumentais, baseadas em métodos essencialmente quantitativos ou em critérios elaborados para medir a eficácia das ações estatais como forma de garantir financiamentos externos, defendo um processo avaliativo substantivo e qualitativo, preocupado com os valores e as ideias que perpassam as políticas públicas, e que incluam os atores envolvidos direta ou indiretamente com sua produção. Dentre os valores orientadores das políticas públicas, considero fundamental lidar com as concepções de justiça social presentes em sua produção, conhecê-las permite entender os modelos e caminhos propostos, e também as concepções de Estado, direitos e cidadania que permeiam todo o processo.

A partir de uma perspectiva mais tradicional, a avaliação é definida como a fase do ciclo de políticas públicas em que se questiona como uma política está funcionando na prática, refletindo sobre os meios empregados e sobre os objetivos e resultados alcançados. Ela permite pensar a eficácia de uma política pública, questionando sua validade, e o sucesso ou falha dos projetos colocados em prática.

A avaliação é a fase do ciclo de políticas públicas em que o processo de implementação e o desempenho da política pública são examinados com o intuito de conhecer melhor o estado da política e o nível de redução do problema que a gerou. É o momento-chave para a produção de feedback sobre as fases antecedentes. (SECCHI, 2013, p.63)

A avaliação é normalmente pensada como a última fase do ciclo das políticas públicas. A noção de ciclos entende a política pública em etapas, abarcando seu processo desde a consecução da agenda até a avaliação de seus resultados. Sabemos que se trata acima de tudo de um recurso didático, que ajuda a pensar a análise da política.

Considerando que uma das principais características das políticas públicas é dada pela indeterminação de seu processo, é extremamente difícil medir o sucesso de uma política utilizando como critério o cumprimento de seus planos e normas originais. 
É preciso adaptar os planos ao curso dos eventos e da experiência acumulada durante o processo de implementação. (De Mario, 2013, p.104)

A partir de uma concepção mais tradicional, como sugere Leonardo Secchi (2013), a avaliação pode ser pensada em três momentos distintos, ex ante, ex post, e in itinere. A primeira se dá no momento de formulação da política, quando o gestor precisa ter informações acerca do impacto que a política ou programa proposto terá na população, para tal realiza-se um estudo de investigação sobre as consequências e os custos entre diferentes alternativas para a condução do projeto que se pretende implementar, sendo que a manutenção do status quo também figura como opção possível, e essa última pode levar o gestor a optar pela não implementação de determinado projeto.

A avaliação ex post é aquela que, de acordo com a noção de ciclos da política, ocorreria ao "final do processo", após a implementação, buscando avaliar os resultados alcançados e os impactos da política. A avaliação initinere, por outro lado,ocorre durante a implementação e visa fazer ajustes mais imediatos.

Sublinho que é preciso ter claro que a avaliação não é uma atividade neutra. Seu intuito e até mesmo seus achados são orientados pelos propósitos e pelos valores de quem a demanda. Assim, uma avaliação externa, feita por grupos não envolvidos com o governo e com a gestão direta da política, terá preocupações diferentes das de uma avaliação realizada por quem está diretamente envolvido com a política. Os resultados de uma avaliação podem ser usados tanto para melhoria dos processos de gestão, como para crítica da eficácia e relevância da política pública, assim como propaganda de governo.

Dessa forma, os resultados de uma avaliação podem servir para mascarar ou esconder fatos, forjando um resultado que favoreça politicamente o governo; ou, ao contrário, se por ventura o governo pretenda interromper uma política bem-sucedida ele pode "carregar as tintas" em fatores negativos e justificar o fim da política. Bem como grupos externos podem fazer a avaliação com o propósito de contribuir com o aprimoramento da política, e não apenas com o intuito de criticá-la.

Pensando em termos de justiça, os atores envolvidos com a avaliação e produção da política podem ter concepções de justiça social conflitantes e uma política pode ser considerada justa ou injusta dependendo da concepção que embasa os critérios utilizados para sua análise e/ou avaliação. Se ampliarmos esse leque de atores envolvidos direta ou indiretamente com as políticas públicas nosso cenário pode ser ainda mais complexo e revelar os diferentes projetos de Estado e suas concepções de justiça social em disputa. ${ }^{3}$

Entretanto, é importante frisar como colocam Michael Howlett; Ramesh e Anthony Perl $(2013$, p.200) que

Isso não significa sugerir que a avaliação de políticas é um processo irracional ou puramente político, sem intenções genuínas de apurar o funcionamento de uma política e seus efeitos. Ao contrário, ela serve como um alerta para a consciência de que confiar apenas na avaliação formal para tirar conclusões sobre o sucesso ou 
insucesso relativo de uma política levará a insights excessivamente limitados sobre os outcomes políticos e suas apurações. Para se extrair o máximo da avaliação de uma política deve-se também levar em conta os limites da racionalidade e as forças políticas que a moldam, sem cair no extremo de acreditar, porém, que a natureza subjetiva das apurações políticas impede que aconteçam avaliações significativas. (HOWLETT; PERL, 2013, p.200)

Portanto, significa assumir que a avaliação não é um processo racional e neutro, e que deve ser compreendido dentro de sua lógica e de acordo com seus propósitos.

Cabe também salientar que é preciso cuidado com os propósitos e resultados de uma avaliação, pois os critérios adotados para determinar se uma política pública é eficiente ou eficaz muitas vezes acabam impondo sobre o gestor exigências que limitam sua atuação ou que podem inclusive perverter os sentidos da política pública, já que em muitos casos a adequação de seu processo de implementação aos parâmetros impostos por avaliadores externos têm importante impacto sobre os resultados alcançados pela política.

Visando garantir a confiabilidade dos resultados da avaliação o esforço volta-se para a definição de critérios, indicadores e padrões, que obviamente, não estão isentos de valores, mas, buscam apresentar-se de forma neutra ao fazer uso de um linguajar rebuscado e tecnicista e apresentando-se a partir de um viés metodologicamente científico. Tais critérios pretensamente neutros se constituem em instrumentos hegemônicos que fornecem modelos e parâmetros ao avaliador e ao público alvo da avaliação. De acordo com Secchi $(2013$, p.63) estão dentre os principais critérios usados pelos avaliadores: a economicidade, uso de recursos; a produtividade; eficiência econômica, relação entre produtividade e recursos utilizados; eficiência administrativa, nível de conformação da execução à métodos preestabelecidos; eficácia, alcance de metas ou objetivos e, equidade, trata da homogeneidade de distribuição de benefícios entre os destinatários de uma política pública.

Esses critérios, é bom que se sublinhe, funcionam como instrumentos a disposição dos mais diferentes modelos de avaliação. Dentre os esforços de avaliação temos tipos que variam dentre foros e meios de avaliações que envolvem avaliadores formais e informais, do governo e da sociedade civil (Howlett; Ramesh; Perl, 2013, p.206). Incluem avaliações advindas do Judiciário; as avaliações técnicas ou administrativas e avaliações políticas.

No Brasil, o papel da avaliação controle e regulação vem sendo exercido pelo judiciário e por órgãos dos diferentes poderes. Destacam-se os Ministérios Públicos Estaduais e Federais que são órgãos independentes, não pertencem a nenhum dos três poderes (executivo, legislativo e judiciário), possuem autonomia e estrutura própria, não podem ser extintos e nem terem suas atribuições repassadas a outra instituição. Também temos atuando na observância das leis e normas as comissões Parlamentares de Inquérito no Legislativo; os Tribunais de Contas aos quais subordinam-se todos os poderes e todos os níveis e âmbitos da administração pública; e órgãos do Executivo, 
pertencentes a administração direta, como as Corregedorias, Controladorias e Ouvidorias.

Em contraposição a tais modelos de avaliação temos as avaliações políticas que são empreendidas normalmente por partidos políticos, think-thanks, e grupos da sociedade civil diretamente envolvidos com a temática ou área alvo da política pública que se propõe avaliar.

Nas avaliações políticas estão em jogo questões como a percepção que a sociedade e os cidadãos usuários da política têm dela; a legitimidade do processo de avaliação; como se deu a participação dos atores nas diversas etapas da política, ou os impactos gerados na qualidade de vida e no macroambiente.

Nesse sentido, as avaliações políticas são aquelas que mais se aproximam de questões substantivas e voltadas para a legitimidade das políticas públicas que remetem ao como a população percebe e avalia a política e, à noção de confiança no governo e nas instituições.

Na próxima seção tratarei da avaliação realizada de uma perspectiva endógena, feita durante a implementação da política e como um instrumento de aprimoramento da gestão pública. Minha análise se baseia no processo de avaliação promovido pela equipe da Ouvidoria Geral do Município de Campinas durante os anos de 2002 a 2009, busco mostrar como uma avaliação endógena articula ideias, valores e precisa levar em consideração a legitimidade da política abarcando as expectativas e percepções que outros atores têm sobre a política. Identifico nessa experiência a adoção uma abordagem epistêmica.

\section{LEGITIMIDADE E SUAS QUESTÕES PARA A AVALIAÇÃO DE POLÍTICAS PÚBLICAS}

Análises e avaliações que se voltam para questões afeitas à legitimidade das políticas ainda não são comuns, mas, tal como propostas por Rothstein (1998, p.103), teriam o mérito de avaliar a política de uma perspectiva substantiva, para além dos esquemas racionalistas usualmente empregados, pois para o autor: "state capacity is more than a matter of program design, casual theories, or organs of implementation. It is also a question of what views citizens hold about the nature of the actually existing state. From a game-theoretical perspective the strategic question for the citizens is if the state as a unit of collective action can be trusted or not."

Para Rothstein a legitimidade das políticas públicas está diretamente relacionada com aquilo que o Estado é capaz de fazer. A abordagem proposta pelo autor diferencia-se dos esquemas analíticos normalmente propostos, pois ele pensa a política a partir de três áreas: desenho, organização e legitimidade. Todas as três são perpassadas por questões substantivas (como problemas concernentes a mudança de objetivos do programa para atender a demandas externas) e de processo (como a política se organizará, centralizada ou descentralizada, como os diferentes níveis do 
sistema político podem ser coordenados, etc). Segundo o autor esses fatores devem ser vistos a partir de uma perspectiva dinâmica, dessa forma o que se aplica em um determinado período não pode ser aplicado em outro, pois "a policy can only work under certain external conditions, and if these conditions chance, the means requisite to achieving the objectives of the program chances as well" (Rothstein, 1998, p.72).

Considero a abordagem formulada pelo autor adequada para os propósitos dessa análise por partir da noção de que as políticas públicas têm a indeterminação como uma de suas características centrais, e por considerar o contexto e o papel dos diferentes atores envolvidos com a política - e suas ideias, para a análise do processo elaboração e organização, bem como dos resultados da política.

Para o autor a legitimidade está diretamente relacionada com a confiança dos cidadãos no Estado e na sua capacidade de ação. Esse processo é marcado por pelo menos três aspectos centrais: a tolerância dos cidadãos à intervenção do Estado; a receptividade das decisões que produzem impacto direto sobre o comportamento de indivíduos ou grupos e, com até que ponto os cidadãos estão dispostos a colaborar para a realização dos objetivos propostos pelas políticas públicas. (Rothstein, 1998, p.105)

A legitimidade também é intimamente relacionada com a democracia representativa e as expectativas dos cidadãos sobre a realização das promessas de governo. Rothstein (1998) sublinha que Weber já afirmava que a legitimidade política estava relacionada a dois aspectos: com (1) a capacidade de os cidadãos poderem democraticamente influenciar as decisões políticas através do voto e da democracia representativa, portanto, com (2) a confiança na organização do sistema político e no processo de implementação da política levado a cabo pelos burocratas, pois essa é a face do Estado com a qual os cidadãos estabelecem contato direto e da qual são mais dependentes. Em outras palavras, uma relação positiva com um "burocrata de nível de rua" - médico, enfermeira, professor - é tão importante para a legitimidade das políticas públicas quanto o reconhecimento do cidadão de que há proximidade entre suas demandas e expectativas e as ações dos governantes eleitos, o que garantiria um certo patamar de representatividade efetiva.

Sobre esses aspectos apresento algumas ponderações, buscando desenvolver os pontos propostos por Rothstein.

Observo que a tolerância ${ }^{5}$ às políticas públicas se desenvolve em situações nas quais temos objeções ou rejeições a uma determinada ideia, ou medida, que orienta a prática política. É possível ter alguma objeção forte a uma determinada ideia e, mesmo assim, tolerá-la. Nesse caso, valores e crenças estão em jogo, e eles se desenvolvem em um espectro que vai desde a concepção de Estado que as pessoas sustentam até questões mais específicas, como se devemos impor condicionalidades aos beneficiários de políticas sociais, a exemplo do debate em torno do Programa Bolsa Família.

Outro ponto é que normalmente a tolerância remete a relações de poder, portanto a condições de desigualdade e de sujeição de uma das partes em relação. Pergunto: 
como pensar a tolerância à intervenção do Estado em uma estrutura de governo (e também de relações sociais) cujas relações são hierarquizadas, desiguais? Tomemos o caso das políticas de saúde como exemplo pontual de relação entre a burocracia e o cidadão. A relação que se constrói entre os profissionais da saúde (principalmente médicos) e os pacientes é profundamente desigual: há uma hierarquia claramente estabelecida que se baseia no saber sustentado por um dos atores e se traduz em uma relação de sujeição, de submissão do paciente ao médico ou à enfermagem. O espaço de contestação é quase inexistente. Se a relação médico-paciente é um exemplo clássico, podemos expandir nosso horizonte e encontrar essa mesma sujeição na relação que se estabelece entre os cidadãos usuários de outras políticas públicas e sua burocracia de modo geral.

Esse é o caso do preenchimento de cadastros para solicitação de benefícios como o bolsa família. Nesse caso, quem detém o conhecimento, tanto técnico como político, é o burocrata que preenche o cadastro e possui os instrumentos e até mesmo o poder de decidir quem está ou não habilitado a receber o benefício. Às vezes, a falta de conhecimento e informação sobre a organização da estrutura pública impede alguém de conseguir uma vaga na "creche" para um filho, de conseguir um tratamento de alta complexidade em saúde pelo Sistema Único de Saúde, ou de impedir uma prisão injusta.

O que temos em muitos casos é uma total submissão dos usuários às regras e normas da instituição e também à vontade dos burocratas, pouco dispostos a compartilhar de seu conhecimento e poder de decisão sobre os processos da política. A tolerância nos exemplos acima justifica-se muito mais pela falta de alternativas imposta ao usuário do que pela confiança que ele tem nos resultados gerados pela política.

Essa é certamente uma das razões das frequentes explosões de violência dos cidadãos usuários diretos da política contra os burocratas de nível de rua. São, por exemplo, comuns os relatos de pacientes que agridem física e verbalmente os funcionários de Centros de Saúde e Pronto Atendimentos, cansados com as longas esperas por atendimento, indignados com a dificuldade de acesso à exames, tratamentos e medicamentos, ou com um tratamento desrespeitoso que receberam de um médico ou enfermeiro. Da mesma forma, os primeiros contatos entre os cidadãos usuários e os atendentes das Ouvidorias públicas são normalmente violentos, pois aqueles, já desgastados por uma série de tentativas malsucedidas de resolverem seus problemas, sistematicamente agridem os atendentes (neste caso os burocratas de rua). Tais agressões normalmente são acusações e generalizações que trabalham com a ideia de que os funcionários públicos são ineficientes, ou vagabundos, e descomprometidos com suas tarefas.

A receptividade e a disposição de colaborar com a política são aspectos que podem ser pensados um como decorrente do outro. A disposição de colaborar com as leis de trânsito, a exemplo da lei seca e dos limites de velocidade; com o pagamento 
de taxas e impostos; com campanhas de vacinação ou de controle de pragas e epidemias - como limpar meu quintal para evitar a proliferação de criadouros do mosquito transmissor da dengue, ou suspender planos individuais de gravidez, adotando o uso de preservativos para evitar o risco de ter um filho acometido por microcefalia em função da proliferação do vírus da zika - depende de uma equação entre ganhos e perdas que é feita individual e coletivamente e uma convergência em torno das ideias que justificam publicamente tais orientações e as obrigações delas decorrentes.

Esses aspectos revelam, além da confiança na instituição e a tolerância em suas ações, a necessidade de valorização coletiva de medidas que a maioria dos cidadãos estejam dispostos a defender, ensejando a disposição de colaborar. Aqui surge mais claramente o papel das ideias e dos valores para a justificação das políticas públicas e, também a importância da confiança nos governantes que por vezes precisam assumir uma atuação mais personalista, com o intuito de reforçar medidas e programas, seja tecnicamente ou através do uso da legitimidade que lhes é garantida pelo exercício da representação política.

A discussão da legitimidade relaciona-se a duas questões também processuais: o contexto, dado pelas condições materiais de implementação das políticas públicas e pelo o que o Estado é capaz de fazer a partir delas; e o nível de discricionariedade dos burocratas e sua capacidade de influência no processo de implementação e nos resultados das políticas públicas.

Sobre este aspecto Rothstein (1998, p.80) lembra que a capacidade de implementação do Estado pode ser alta, mesmo quando há falta de conhecimento técnico por parte dos gestores, as incertezas a respeito das possibilidades de se atingir um resultado positivo são grandes, ou quando há um "buraco negro no processo democrático" ${ }^{\prime 6}$. Dessa forma, é preciso considerar vários aspectos para a análise do processo de legitimidade das políticas.

O caráter processual da legitimidade relaciona-se diretamente com os modelos organizacionais adotados. Estes podem variar de acordo com o contexto e as condições disponíveis: um modelo legal-burocrático que enseje a confiança nas normas e regras das instituições, que se forem de amplo conhecimento e mostrarem-se estáveis ao longo do tempo dotam o cidadão de uma certa capacidade de predição; e um modelo profissional que confia a uma determinada categoria a implementação das políticas públicas em virtude de sua expertise no tema; um modelo corporativista, que busca incorporar representantes de determinadas corporações envolvidas diretamente com o tema e o escopo da política em seu processo de implementação para garantir que a política leve suas demandas em consideração; um modelo participativo, que inclua o cidadão nos processos decisórios, e por fim, um modelo politicamente orientado, que obrigue os governantes eleitos a tomarem decisões pois possuem legitimidade garantida pelo voto.

O objetivo é enfatizar algumas ideias sobre o caráter substantivo da legitimidade e tentar incorporar aos elementos trabalhados por Rothstein as expectativas e a 
percepção que os cidadãos, usuários diretos da política, e os burocratas, principalmente os de nível de rua, têm sobre a política. Incorporar as expectativas e a percepção que se tem da política nos remete às ideias e aos valores sustentados pelos atores diretamente envolvidos com a sua implementação e avaliação.

Os burocratas de nível de rua são de especial interesse em razão do nível de discricionariedade que caracteriza sua atuação e pela relação que estabelecem com os usuários da política. Por ser uma relação direta, desenvolve-se entre esses atores uma proximidade de interesses e de percepções de mundo que têm importante impacto sobre a política.

Os usuários normalmente têm uma percepção mais individualizada de seus dramas e necessidades, aos seus olhos, as suas demandas têm um determinado grau de urgência que requerem uma atenção especial perante as demais. Sem desconsiderar que o sofrimento e seus sentidos têm um viés subjetivo, essa percepção de urgência é usada como um mecanismo de pressão sobre a burocracia de rua que, ao ser adotado pelos usuários das políticas públicas leva a uma ocultação do caráter coletivo de suas demandas?.

Por sua vez, os burocratas/gestores possuem uma percepção mais coletiva dos processos que envolvem as políticas públicas e, por isso, despersonalizam as demandas, enquadrando o indivíduo que lhes cobra um determinado atendimento ou serviço em um quadro mais geral de necessidades, que em muitos casos requerem ações gerais, ampliadas, para além dos atendimentos pontuais.

Esses burocratas têm a possibilidade e capacidade de decidir sobre o uso das normas das políticas públicas, sobre quais demandas priorizar, sobre o tempo para seu atendimento e, se a resolução será em um âmbito mais coletivo ou individualizado. Essa discricionariedade confere importante poder aos burocratas de nível de rua e têm impacto direto sobre a percepção que os usuários terão/têm sobre a política.

Essas decisões não apenas são tomadas seguindo as normas e regras institucionais previamente estabelecidas e que orientam o exercício de sua função, mas também de acordo com os valores e as ideias dos atores envolvidos. Esses valores podem inclusive dar às políticas públicas orientação diferente daquela presente em seu desenho e têm impacto direto sobre a percepção que os usuários diretos e os cidadãos, de forma geral, têm da política. Ao mesmo tempo, propiciam a formação de uma cultura de relações entre usuários e burocratas que escapa aos ditames institucionais da política.

Esse fenômeno remete à noção de mediações empregada por pesquisadores das redes sociais, perspectiva para a qual os indivíduos são mediadores que constroem pontos de conexão por estarem nas margens ou nas fronteiras de determinados grupos sociais. Esse processo de mediação é fundamental para a elaboração das políticas públicas. Ao expor a perspectiva de Mische, Lotta $(2015$, p.67) ressalta que "a conciliação provisória de identidades, projetos ou práticas, para ela [Mische], é o que entendemos como o processo de implementação da política pública quando há uma conciliação provisória do processo de comunicação e realização de práticas 
entre o agente implementador e os beneficiários, portanto, quando se efetiva a implementação da política pública".

Durante o processo de mediação os atores desenvolvem alguma forma de conciliação, coordenação e alinhamento de ideias. Como apontado por Lotta (2015), a interação entre os usuários e os funcionários públicos altera os processos de implementação e os resultados das políticas públicas e (acrescento), por isso são fundamentais para a avaliação e legitimidade das políticas.

\section{AVALIAÇÃO ENDÓGENA E A EXPERIÊNCIA DA OUVIDORIA GERAL DO MUNICÍPIO DE CAMPINAS}

A prática das Ouvidorias Públicas é elucidativa das questões anteriormente trabalhadas, apontarei alguns elementos e processos presentes no trabalho das Ouvidorias Municipais, tanto a partir de minha pesquisa de mestrado como a partir de minha experiência enquanto gestora e conselheira consultiva na Ouvidoria Geral do Município de Campinas entre os anos de 2002 e 2009 (DE MARIO, 2011).

As Ouvidorias são órgãos que no Brasil ganharam força durante a redemocratização e passaram a ser implementadas como parte do projeto democrático participativo ${ }^{8}$. Sua função primordial é garantir o atendimento e a realização dos direitos do cidadão. Os ouvidores são representantes do cidadão dentro do governo e, enquanto seus porta-vozes, têm como objetivo central garantir que as demandas que lhes são levadas pelos cidadãos (desde que pertinentes) sejam atendidas ou, em caso de impossibilidade, encaminhadas para outras instâncias como as Corregedorias ou os Ministérios Públicos que têm maior (e outro) escopo e poder de atuação.

As Ouvidorias são órgãos mediadores: elas recebem demandas dos cidadãos, e as apresentam aos gestores responsáveis por sua execução. Elas também são o fim do caminho, pois são a última instância para a qual o cidadão pode recorrer dentro da estrutura do poder executivo ${ }^{9}$. Tais demandas podem ser reclamações sobre ausência ou falta de qualidade das políticas e serviços públicos; sugestões, elogios e até mesmo denúncias de crimes cometidos por funcionários públicos. Sobre estas últimas, é importante observar que as Ouvidorias não têm poder de punição, e como nos demais casos, cabe a elas encaminhar as denúncias recebidas para os órgãos e instâncias competentes por sua investigação e resolução.

As Ouvidorias também podem ser acionadas pelos próprios funcionários públicos que desejem realizar reclamações ou denúncias crimes. Normalmente, tais reclamações referem-se a relações de trabalho, como assédio moral, perseguição, falta de condições de trabalho, ou denúncias de irregularidades ou ilegalidades cometidas por colegas de trabalho.

Na tentativa de darem aos cidadãos uma resposta qualificada, ou seja, a resolução de seu problema ou uma justificativa detalhada garantindo o acesso à informação, as Ouvidorias realizam uma constante avaliação das políticas públicas e dos atendimentos 
prestados. Neste sentido, sua riqueza é justamente a informação que possuem ou que são capazes de reunir.

Ao receber uma denúncia, a Ouvidoria recolhe o relato do cidadão, os problemas apontados, seus questionamentos e suas expectativas. O passo seguinte é consultar o servidor público ou setor/departamento responsável pela prestação do serviço reclamado, momento no qual obtém-se informações sobre os porquês que envolvem a reclamação. No caso de uma reclamação de falta de qualidade ou não prestação do serviço são variadas as razões elencadas pela burocracia: falta de servidores, de equipamentos, de verba, atraso em licitações, questões legais, conflito de entendimentos sobre um serviço a ser prestado por parte do próprio funcionalismo público, ou ação de um servidor específico que originou a reclamação.

É a partir do contato com os cidadãos e, geralmente, com os burocratas de nível de rua que as Ouvidorias são capazes de reunir um rico material sobre as capacidades, as dificuldades e os dilemas enfrentados para a prestação de um determinado serviço público. Tomando a política de saúde como exemplo, ao reunir reclamações sobre falta de médicos, equipamentos, medicamentos, demoras para realização de consultas, exames e procedimentos, as Ouvidorias são capazes de fornecer um diagnóstico que nem os avaliadores externos e nem os técnicos, gestores e chefes do executivo, hierarquicamente e organizacionalmente distantes dos burocratas de nível de rua, possuem. Através dessa sistematização dos dados, as demandas que aos olhos dos cidadãos - usuários diretos das políticas públicas - são individuais ganham caráter coletivo, pois as Ouvidorias conseguem reunir várias reclamações da mesma natureza e, a partir da sistematização desse material, agir de forma propositiva, apontando soluções.

Pensando no processo avaliativo, as Ouvidorias o realizam de duas formas: uma mais abrangente, que abarca ações de outras secretarias de governo, a partir da sistematização e análise dos dados que são capazes de reunir; e outra, interna, ao observarem a sua capacidade resolutiva e analisarem o conteúdo das respostas que encaminham aos cidadãos que as procuram.

A primeira depende de uma atuação coordenada com outras instâncias do governo e com os secretários das pastas envolvidas. Por exemplo, é possível produzir relatórios quantitativos e análises qualitativas sobre as políticas reclamadas e discuti-las com as Secretarias de governo envolvidas com sua implementação, visando soluções coletivas que envolvam diferentes níveis hierárquicos da estrutura funcional e, por vezes, Secretarias de Governo com atuação indireta, como as de Recursos Humanos ou de Finanças. Como as Ouvidorias não têm por função a execução das políticas públicas, o que elas fazem (ou podem fazer) é apresentar recomendações aos demais gestores e discutir os resultados alcançados a partir da interação que estabelecem com usuários e com a burocracia, principalmente a de nível de rua.

Entendo essa forma de atuação como um processo de avaliação contínua e política cujo sucesso depende da aceitação dos demais gestores desse papel 
desempenhado pelas ouvidorias e também da sua disponibilidade de atuação e capacidade de incorporar dois grupos de atores normalmente marginalizados nas avaliações e análises de políticas públicas. Refiro-me aos usuários e burocratas de nível de rua, marginalizados seja por sua distância física dos técnicos de gabinete que tomam decisões sobre a política, ou por falta de expertise para participar dos processos deliberativos. Ambos também estão comumente alienados dos processos deliberativos que decidem sobre a implementação da política.

Entretanto, na prática são esses grupos que decidem e cumprem importante papel no resultado alcançado pelas políticas. Dentre as reclamações recebidas pela Ouvidoria de Campinas sobre a qualidade do serviço de saúde, cito o caso de uma negativa para retirada de medicamento em um Centro de Saúde (CS) do município. O reclamante relatou que foi ao CS retirar um medicamento e foi informado pela funcionária da farmácia que o medicamento estava em falta. Entretanto, ele ficou sabendo por outro usuário do CS que o remédio que necessitava não estava em falta. Quando interpelada pela Ouvidoria, a funcionária relatou que não entregou o medicamento porque a pessoa era de classe média, tinha dinheiro para comprar em uma farmácia e que não deveria "tirar medicamento de quem necessitava" (De Mario, 2011). Essa foi uma decisão tomada pela funcionária, burocrata de nível de rua, decisão orientada por valores morais e princípios de justiça social pessoais, e que revelou uma visão assistencial do SUS, entendendo saúde como um bem que deve ser garantido aos mais pobres pelo Estado, ao invés de um direito pleno de cidadania, contrariando os princípios do SUS.

Como apontei anteriormente, essa relação constrói e reconstrói a política pública em seu cotidiano, pois é a articulação desses valores que orienta as decisões pontuais e imediatas e que também influencia na avaliação e na legitimidade da política. Relação cotidiana que também é uma forma que os cidadãos têm de participar da política e de cobrar ações do Estado e que pode ter tanto impacto nos resultados alcançados quanto em espaços institucionalizados como os conselhos deliberativos e consultivos. Os espaços institucionalizados de participação normalmente excluem o usuário direto da política que, na prática são representados por movimentos sociais e/ou associações civis com as quais nem sempre têm contato direto. Além do mais, neles as discussões são conduzidas pelos técnicos e as decisões tomadas pelos gestores, que nem sempre levam em consideração aquilo que foi proposto pelos representantes da sociedade civil, pois é possível articular um discurso tecnicista para justificar uma tomada de decisão diferente das reivindicações e sugestões apresentadas.

O mais importante é que em uma avaliação endógena, realizada a partir dos dados reunidos pelas Ouvidorias, se mobiliza o discurso do cidadão e do servidor responsável pela execução da política, reunindo suas frustrações, suas expectativas e as suas percepções da política. Este material, quando sistematizado e analisado pela equipe da Ouvidoria e entregue tanto aos gestores como aos cidadãos propicia um diagnóstico epistêmico e uma avaliação contínua das políticas públicas que 
questionem seus resultados a partir de critérios substantivos e incorporem questões relativas à sua legitimidade.

Os resultados dessa avaliação seguem dois caminhos externos que têm impacto direto sobre seu próprio trabalho e abrangem as demais áreas do governo. $O$ primeiro é sua publicização por meio dos relatórios de prestação de contas divulgados para a cidadania que constitui dever legal de garantia de acesso à informação das Ouvidorias e, o segundo, é o debate envolvendo os gestores de outras secretarias de governo promovido pela sistematização dos dados e informações a serem debatidas visando a melhoria dos serviços prestados.

Os relatórios de prestação de contas aos cidadãos perdiam a subjetividade própria dos dados produzida pela Ouvidoria e não ensejavam uma avaliação substantiva em função do modelo utilizado para sua divulgação, a exemplo de gráficos e tabelas que relacionavam números de atendimentos por área de governo, principais programas ou serviços reclamados, e tempo para o envio de respostas versus capacidade de resolução. Divulgava-se também um perfil social das pessoas que procuravam o órgão, incluindo sexo, faixa etária, região de moradia, profissão, raça e faixa de renda.

Foi possível através de esses relatórios saber quais eram os serviços mais reclamados e o tempo que a Ouvidoria levava para encerrar as reclamações, sem divulgação sobre seus conteúdos ou problemas enfrentados pela administração pública para atender à demanda social. Tratava-se um retrato mensal estático, de um recorte específico no tempo, produzido pelo software do órgão a partir de variáveis que foram decididas pela própria equipe. Anualmente o(a) Ouvidor(a) produzia uma análise qualitativa, como um relatório no qual procurava explicar os dados quantitativos publicados mensalmente e abordar os principais problemas e as principais ações empreendidas pela Ouvidoria.

Esses relatórios tinham escopo e alcance limitado, e claramente propiciavam à sociedade uma leitura parcial, explicitando um viés do trabalho da Ouvidoria a partir de um conteúdo cuidadosamente elaborado para que o governo não fosse exposto de forma essencialmente negativa. Tais relatórios ensejavam críticas e muitos questionamentos, principalmente por parte da imprensa municipal, que ora questionava a eficácia das áreas mais reclamadas, ora da própria Ouvidoria.

O outro nível de avaliação que se desenvolve a partir da atuação das ouvidorias é aquele que se refere ao seu próprio desempenho. Nesse caso, os relatórios estatísticos de divulgação pública eram somados aos dados substantivos das reclamações diariamente trabalhadas pela equipe para análise do nosso trabalho. Enquanto gestora, participei de discussões e processos de avaliação endógena que passavam por avaliar os procedimentos internos do órgão, visando melhorar tempos de encaminhamento e andamentos dos processos que eram instaurados, a qualidade da resposta que dávamos ao cidadão, e também os sentidos do nosso trabalho.

De uma perspectiva mais prática, esses processos avaliativos ensejavam discussões em equipe sobre a eficiência e adequação dos procedimentos adotados, sobre a 
capacidade de atendimento ao público e de análise da demanda recebida, sobre a elaboração e geração dos dados que serviam de base para os relatórios quantitativos de prestação de contas. Enfim, questões enfrentadas pela equipe em seu cotidiano e que sempre precisavam ser ajustadas ao contexto social e político, e às condições materiais disponíveis ao órgão.

De uma perspectiva substantiva, tratava-se de uma discussão complexa e que perpassava o entendimento que tínhamos do papel a ser desempenhado pelo órgão. $O$ mais importante era dar uma resposta ao cidadão ou resolver a demanda apresentada. Perpassa também por discussões sobre o direito à informação e as interpretações dessa lei, e sobre a capacidade e o dever de o Estado prestar determinados serviços públicos.

O primeiro ponto remete ao que chamo de "dilema existencial das ouvidorias", a reposta a esse dilema é crucial para definir seus princípios, seus objetivos e sua forma de atuação, ela também mobiliza valores e concepções de Estado, democracia e cidadania. Parte da equipe da Ouvidoria do município de Campinas (SP), naquele período, entendia que era papel do órgão dar uma reposta ao cidadão independentemente de seu conteúdo, enquanto outra parte entendia que se devia cobrar das secretarias de governo reclamadas pelos a resolução definitiva do problema apresentado pelos cidadãos $^{10}$.

Dar uma resposta significava dizer a um usuário do SUS que reclamava a falta de um medicamento, ou de profissionais, que a falta se justificava por falta verba, ou porque os concursos estavam parados, ou porque havia algum problema na licitação, e que assim que possível a sua demanda seria atendida. Essa resposta não resolvia o problema reclamado, apenas dava ao cidadão alguma satisfação, que podia inclusive ser "falsa"11. Ressalto que o conteúdo das respostas é manipulado pelos servidores que podem optar por ocultar fatos ou elementos importantes por julgarem que os usuários não precisam ter acesso a determinadas informações, ação que ocorre dentro do seu escopo de discricionariedade.

A questão central sempre debatida era a de que as respostas que se limitavam a "dar uma satisfação" geravam grande insatisfação por parte dos usuários com relação ao trabalho da Ouvidoria, insatisfação que apenas se somava a uma anterior: aquela que impulsionou a procura do órgão. Reforçava-se, assim, a sensação de ineficiência que aquelas pessoas já tinham dos serviços e do funcionalismo públicos, sensação que se transformava em indignação e raiva canalizada diretamente sobre a equipe da Ouvidoria que recebia sempre a mesma pessoa, de novo e de novo, sempre com a mesma reclamação.

Suplantar esse quadro dependia do entendimento que a equipe tinha sobre o papel do órgão, e sobre as atuações individuais de cada servidor. É importante notar a perversidade embutida na situação, dar uma resposta significava encerrar um protocolo de atendimento e considerá-lo resolvido, portanto arquivado; no final da linha isso significava estatísticas positivas sobre a atuação da Ouvidoria, que em 
tempo hábil tinha recebido uma reclamação e resolvido, e provava a eficiência de sua equipe nos relatórios estatísticos mensais que eram publicados no site do órgão como forma de atender ao seu dever de prestação de contas à sociedade.

Era a imagem publicamente construída da Ouvidoria que estava em jogo, era a existência e manutenção do órgão dentro da estrutura institucional governamental que estava em jogo, era a sua legitimidade que estava em jogo. Não considerar os "protocolos gerados por reclamação" como resolvidos perante uma reposta não resolutiva enviada ao cidadão que reclamava gerava relatórios de atividade extremamente negativos, que levavam a construção de uma imagem negativa da atuação da equipe da Ouvidoria em si, pois a leitura dos dados pelo público geral é sempre mais imediatista e simplista o que decorre também do modelo adotado para a divulgação dos dados, como mencionei anteriormente - afinal uma coisa é o gráfico ou dado estatístico, que apresenta um retrato momentâneo e por vezes superficial, outra é a explicação desse dado que precisava ser qualitativa e substantiva, e cujo conteúdo gerava uma "contrapropaganda" de governo.

Soma-se a isso uma outra faceta: as disputas de poder que se construíam dentro do governo entre os secretários de governo e o ouvidor. O ouvidor era tido pelos primeiros como um intruso, incomodo que ficava o tempo todo apontando problemas, às vezes sabia mais de suas pastas do que eles mesmos em razão da relação que a Ouvidoria estabelecia com a burocracia de nível de rua, e ainda por cima tinha a petulância de Ihes dizer o que fazer. Óbvio, considerando esse jogo o "melhor" era que a Ouvidoria apenas encaminhasse as respostas, sem questionar seu conteúdo, sem estimular o cidadão a questionar, sem dar informações "desnecessárias" que poderiam empoderar quem reclamava.

Mas a outra faceta que incomodava a equipe era oriunda de uma determinada concepção de democracia, cidadania e de Estado e, portanto, de justiça social que sustentava e justificava a existência do órgão. As reuniões internas de avaliação do trabalho da equipe eram perpassadas por uma discussão substantiva e normativa que mobilizava os valores não apenas da equipe, mas de um contexto de democracia participativa e das concepções de justiça social pertinentes a esse projeto. Por sua vez, os cidadãos que procuravam a Ouvidoria por mais que não formulassem suas expectativas nesses termos e, por mais que por muitos momentos parecessem estabelecer uma relação de submissão ou de clientelismo com o Estado, entendiam que os direitos sociais que reclamavam eram bens fundamentais pelos quais valia a pena lutar e valorizavam a democracia participativa.

Era essencialmente na relação construída entre a equipe da Ouvidoria e as pessoas que procuravam o órgão que se construía a sua legitimidade, e menos na relação que era estabelecida com os demais gestores e membros do governo. Defendo que esse processo demonstra que não é possível dissociar avaliação e legitimidade na análise das políticas públicas. No caso apresentado os processos avaliativos endógenos realizados de forma contínua, tanto os desencadeados pela atuação da Ouvidoria que 
se estendiam para o todo do governo - convocado a se olhar no espelho, como aqueles internos levados a cabo pela equipe em decorrência da obrigatoriedade de prestação de contas e também da vontade do gestor que coordenava a equipe, requeriam uma reflexão sobre os sentidos do trabalho desenvolvido e sobre a legitimidade do órgão.

\section{CONSIDERAÇÕES FINAIS}

É importante notar que a avaliação assim feita não se restringe a uma análise racionalista, não visa simplesmente verificar se o que estava previsto no desenho foi cumprido e nem trabalha com os critérios de verve tecnicista apontados no início deste artigo (forma de olhar que negligencia toda a complexidade e incerteza que são inerentes às políticas públicas); bem como não está preocupada apenas com a produção de dados quantitativos de atendimento.

Em suma, considero que a análise dos dados obtidos pelas Ouvidorias possibilita uma avaliação endógena das políticas públicas, contínua, rigorosa tecnicamente e simultaneamente política e participativa, pois este tipo de avaliação, ao mesmo tempo em que é global e não deixa de considerar dados e referências metodológicas importantes e questões relativas ao processo e aos resultados alcançados, também trabalha com uma abordagemepistêmica ${ }^{12}$ que se ancora em questões relativas à legitimidade da política, pois considera os aspectos substantivos contidos na fala dos cidadãos e dos servidores.

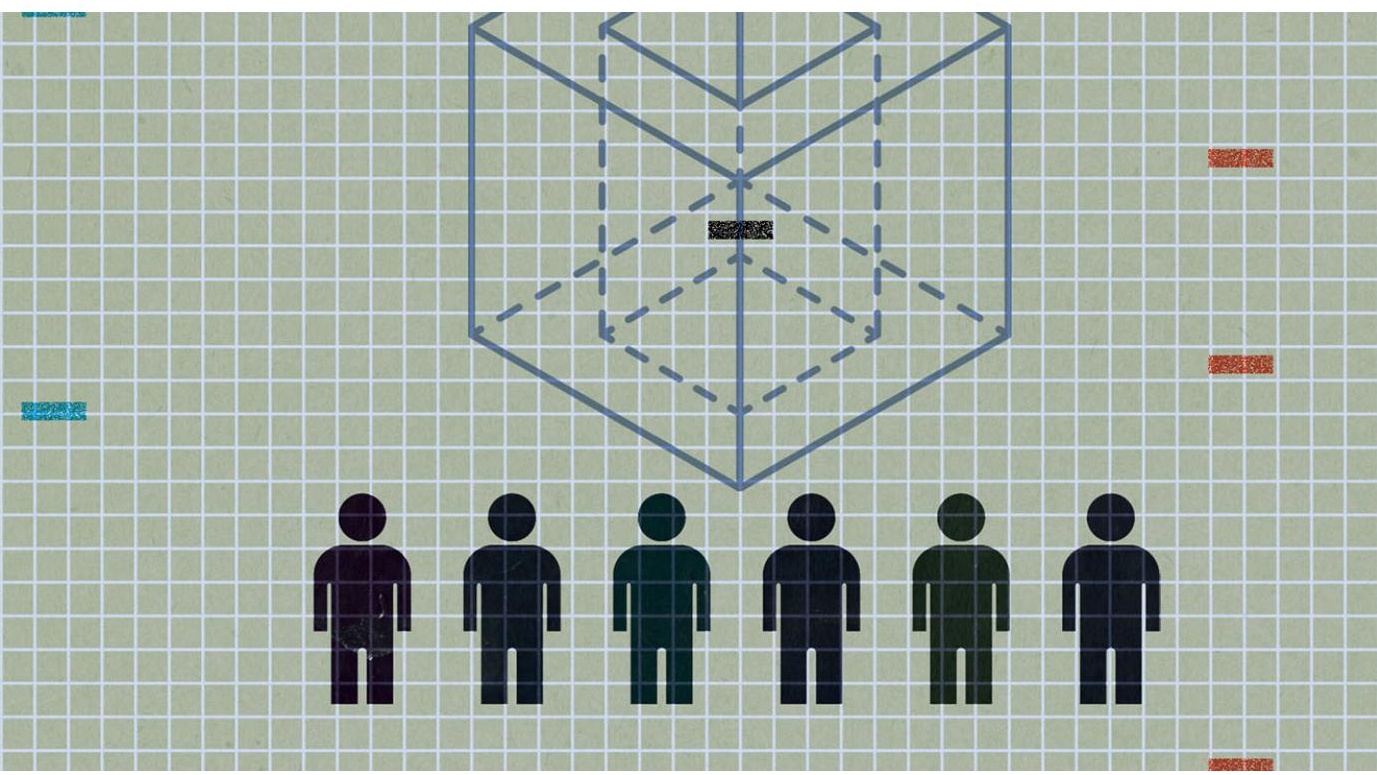


Nesse sentido, considerações epistêmicas nos levam a refletir sobre os conteúdos e os conhecimentos que estão na base dos procedimentos adotados e das decisões tomadas ao longo da produção de uma política pública. Isso não significa sustentar um argumento "epistocrático", o que acarretaria em avaliações cujos critérios recairiam essencialmente sobre as capacidades dos experts e seu saber técnico qualificado necessário para a implementação da política; pois esse saber apesar de importante não serve sozinho à justificação política das políticas públicas. Assim, o cidadão e os burocratas de nível de rua, atores pouco valorizados pelas análises e avaliações de políticas públicas, cumprem papel fundamental nesse processo. E, em contextos de democracia participativa espera-se que a percepção que esses atores têm da política, suas demandas e expectativas estejam no centro do diagnóstico elaborado. Trata-se, por um lado, de incorporar as opiniões e ideias sustentadas pelos atores diretamente envolvidos com a política, seja enquanto usuário seja enquanto produtor direto e, por outro lado, de refletir mais sobre os sentidos da discricionariedade contida na ação dos burocratas de nível de rua e seus impactos sobre a política.

Busquei demonstrar ao longo da descrição do processo avaliativo ensejado pela Ouvidoria como e porque avaliação e legitimidade precisam ser pensadas de modo relacional. O processo avaliativo endógeno ao incorporar as percepções e expectativas dos cidadãos e dos burocratas lida com os elementos definidores da legitimidade aqui trabalhados.

Apesar de o foco deste artigo ser o trabalho das Ouvidorias Públicas esse tipo de avaliação pode ser feita por todos os órgãos ou programas públicos. A avaliação endógena deve ser contínua e requer um método de coleta e sistematização dos dados que seja elaborado pela equipe. Sua vantagem está na possibilidade de uma revisão de processos internos e de reflexão sobre os sentidos do trabalho e sobre os resultados alcançados raramente propiciado por avaliações externas que seguem critérios muitas vezes orientados por valores não condizentes com os da política avaliada.

É evidente que essa perspectiva de avaliação deverá enfrentar um importante debate para a elaboração de métodos, formas de análise e diagnósticos que possibilitem uma avaliação substantiva e política das políticas públicas. Porém, sem dúvidas, exemplos como estes das Ouvidorias apontam para um caminho que deve ser melhor analisado e que pode nos fornecer importantes pistas para seu desenvolvimento. 


\section{Notas}

'Remeto ao debate normativo das teorias da justiça. Considero que a teoria da justiça liberal-igualitária de John Rawls e os debates promovidos a partir dela por autores como Amartya Sen, Axel Honneth, Nancy Fraser e Rainer Forst constituem importante parâmetro normativo para o debate da justiça social brasileiro.

${ }^{2}$ É importante não perdermos do horizonte os interesses que orientam tais exigências e parâmetros de aferição de qualidade das políticas públicas alinhados aos ditames do Consenso de Washington e a uma visão estrita e elitista de democracia que não se coaduna, ao menos em seus propósitos, com os princípios orientadores das políticas públicas no Brasil pós-1988 e com o processo democrático participacionista que marca as relações políticas na América Latina nos últimos 20 anos.

${ }^{3}$ Desenvolvo essa questão no meu livro "Saúde como questão de justiça" (2016).

${ }^{4}$ Desenvolvo melhor a abordagem de Rothstein em meu livro "Saúde como questão de justiça" (2016).

${ }^{5}$ Ver: "The Power of Tolerance: a debate" / Wendy Brown and Rainer Forst; edited by Luca Di Blasi and Christoph F. E. Holzhey. pages cm. - (New directions in critical theory) (New York, Columbia University Press, 2014)

${ }^{6}$ Sobre o processo decisório e a relação entre o cidadão e o burocrata de nível de rua Rothstein (1998, p.80) afirma: "many decisions of very great import for individual citizens are made by local public organs and individual officials. What we might call a black hole of democracy appears here, that is, it can be difficult (well-nigh impossibile, in fact) to hold the administration and officials who decide about the welfare of the citizens in any way responsible for their actions. The elected politicians thus have but limited influence over actual substance of public policy - or, expressed more directly, over what the state in these cases actually does with the citizens. (...) This places heavy demands on (a) the organization of the program in question, and (b) the legitimacy of the measures taken."

${ }^{7}$ Ressalvo que essa percepção está baseada na minha experiência como gestora e na análise que realizo do papel das Ouvidorias Públicas.

${ }^{8}$ Em texto anterior argumento que as Ouvidorias não são espaços de deliberação política, sua função primordial é garantir transparência e acesso à informação através da prestação de contas ao cidadão, somada ao controle que sobre a qualidade das políticas públicas e sobre as ações dos gestores públicos. São órgãos cuja função aproxima-se mais dos princípios da democracia representativa do que da participativa, pois o Ouvidor enquanto mediador representa o cidadão e defende seus direitos perante o Estado. Dependendo de como o ouvidor exerce esse papel é possível afirmar que demandas são incorporadas e modificam o processo de implementação das políticas públicas, mas sem que haja participação direta do cidadão nesse processo que é fechado e orientado por uma lógica tecnocrática.

${ }^{9}$ Minha análise é sobre o papel das Ouvidorias no poder executivo não obstante as Ouvidorias estarem presentes em todas as esferas de poder e nos diferentes âmbitos de governo. É importante salientar que não há um consenso doutrinário e uma padronização da atuação das Ouvidorias brasileiras, entendese que elas devem ser o último órgão a ser acionado para resolução de problemas considerando a estrutura institucional a qual pertencem e que os ouvidores devem ter status igual ou superior aos demais secretários de governo (no caso do poder executivo), ou a instâncias a ele correlatas, e autonomia para que se possa garantir uma atuação efetiva. Para mais informações consultar: http://www.cgu.gov.br/ Publicacoes/ouvidoria/arquivos/ogu-implantacao-unidade-ouvidoria.pdf

${ }^{10}$ Essa discussão não era feita apenas no âmbito da Ouvidoria de Campinas, tratava-se de um debate enfrentado também em fóruns mais amplos, como a ABO - Associação Brasileira de Ouvidores e Ombudsman e os espaços criados pela Ouvidoria Geral da União, desses debates participavam ouvidores de diferentes municípios e instâncias de governo. Embora ainda não houvesse um consenso normativo acerca de seus propósitos, os anos 2000 vivenciaram um rápido crescimento no número de Ouvidorias o que gerou uma importante heterogeneidade institucional e a necessidade de se chegar a um consenso normativo visando um modelo de ouvidorias públicas.

${ }^{11} \mathrm{Nem}$ sempre a informação era dada por completo para o reclamante, principalmente quando envolvia dados sigilosos ou suspeitas de ilícitos cometidos por funcionários públicos, informações que precisavam ser devidamente apuradas e não podiam se tornar públicas.

${ }^{12}$ Estou usando a noção de abordagem epistêmica a partir dos sentidos propostos por David Estlund (2008), ao refletir sobre a autoridade e a legitimidade das decisões tomadas em processos democráticos. Estlund argumenta que está implícita à noção de democracia a atribuição de - algum - valor à opinião 
das pessoas, nas palavras do autor: "a razão pela qual queremos que as opiniões das pessoas sejam consideradas é que acreditamos que suas opiniões sejam qualificadas, inteligentes, mesmo que não tenhamos um alto grau de expectativa, ao menos acreditamos serem melhores do que jogar uma moeda" (ESTLUND, 2008, p.06). Ou seja, há uma dimensão epistêmica que justifica a autoridade democrática, e que deve ser contemplada por uma perspectiva política de avaliação e por uma análise que questione a legitimidade da política.

\section{Referências}

BROWN, W.; FORST, R. The Power of Tolerance: A Debate (ed. Luca Di Blasi; Christoph F. E. Holzhey). New York: Columbia University Press, 2014.

DE MARIO, C. Ouvidorias Públicas Municipais no Brasil. São Paulo: Paco Editorial, 2011.

DE MARIO, Camila. Saúde como questão de justiça. São Paulo: Paco Editorial, 2016.

DE MARIO, C., LAISNER, R., GRANJA, R. Avaliação de Políticas Sociais e participação popular: uma abordagem política. O Social em questão (PUC-RIO), ano XIX, n. 36, p. 39-64, 2016.

ESTLUND, D. Democratic Authority. A Philosophical Framework. Princeton University Press, New Jersey, 2008

HOWLETT, M.; RAMESH, M. \& PERL, A. Política Pública. Seus ciclos e subsistemas. Uma abordagem integral. Tradução técnica. Francisco Heidemann. Rio de Janeiro: Elsevier, 2013.

LAISNER, R., DE MARIO, C. G. Os desafios da avaliação de políticas públicas como instrumento estratégico de gestão e de controle social. Revista de Politicas Publicas (UFMA), v. 18, p. 619-630, 2014.

LOTTA, G. Burocracia e Implementação de Políticas de saúde. Os agentes comunitários na estratégia saúde da família. Rio de Janeiro: Editora Fiocruz, 2015.

ROTHSTEIN, B. Just Institutions Matter. Cambridge: Cambrigde University Press, 1998.

SECCHI, L. Políticas Públicas. Conceitos, esquemas de análise, casos práticos. São Paulo: Censage Learning, 2013.

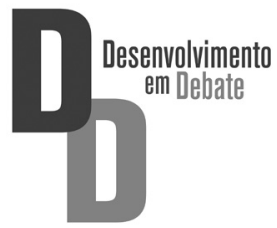




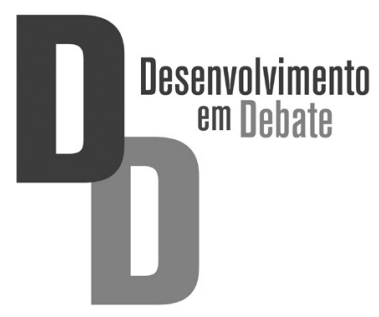

